\title{
(쇼
}

\section{Cortical Blindness and Bilateral Occipital Haemorrhage due to Warfarin Overdose}

\author{
Warfarin Toksisitesine Bağlı Bilateral Oksipital Hematom ve Kortikal Körlük
}

\author{
Mehmet Özgür Erdoğan', Rasim Yorulmaz' , İsmail Tayfur', Özlem Giritli', Seçil Telli Erdoğan² \\ 'Haydarpaşa Numune Eğitim ve Araştırma Hastanesi, Acil Tıp Kliniği, İstanbul, Türkiye \\ ${ }^{2}$ Haydarpaşa Numune Eğitim ve Araştırma Hastanesi, Radyoloji Kliniği, İstanbul, Türkiye
}

\section{ABSTRACT}

Bleeding is a common complication of anticoagulant agents. Rising numbers of patients requiring warfarin, as well as increasing long term use, causes some haemorraghic complications. Intracerebral haemorrhage is one of these complications. An 88 year old patient was admitted to our emergency department with acute loss of sodium ( $5 \mathrm{mg} /$ day) visual acuity. INR was 6.24 in laboratary findings. The patient had a stroke three years previously and used warfarin sodium ( $5 \mathrm{mg} /$ day) for anticoagulation. Bilateral occipital haemorrhage was diagnosed in cerebral tomography. The patient was discharged from neurological care 20 days after admission. We suggest that the incidence of cerebral haemorrhage due to warfarin overdose will increase due to growing rates of anticoagulant treatment in the population.

Keywords: Warfarin, blindness, occipital haemorrhage Received: 07.08.2011 Accepted: 19.12.2011

\section{ÖZET}

Kanama, antikoagülan ajanlarının sık gözlenen bir komplikasyonudur. Warfarinin artan sayıda hasta tarafından uzun süreli kullanımı, çeşitli kanama komplikasyonlarını beraberinde getirir. Intraserebral kanamalar da bu komplikasyonlardan biridir. Seksensekiz yaşında erkek hasta sabah saatlerinde başlayan ani bilateral görme kaybı şikayeti ile acil servisimize başvurdu. Laboratuar incelemelerinde INR değeri; 6.24 ölçüldü. Üç yıl önce inme geçirdiği ve sonrasında oral warfarin sodyum (5 mg/gün) aldığı öğrenildi. Beyin tomografisinde bilateral oksipital bölgede lokalize serebral hemoraji ile uyumlu görünüm izlendi. Kanama alanında regresyon gözlenen hasta, yatışının 20. gününde nöroloji kliniğimizden taburcu edildi. Sonuç olarak bu ilaçların kullanımlarının artacağı açık olup tedavi gelişiminde ise anlamlı ilerleme olmaması bu tür mortalitesi ve morbiditesi yüksek intrakranial kanamaların ileride daha sık görülebileceğini düşündürmektedir.

Anahtar Kelimeler: Warfarin, körlük, oksipital kanama Geliş Tarihi: 07.08.2011 Kabul Tarihi: 19.12.2011

\section{Giriş}

Warfarin, günümüzde tromboemboli profilaksisinde ve tedavisinde sık kullanılan bir ilaçtır. Artan sayıda hasta tarafından uzun süreli kullanımı çeşitli kanama komplikasyonlarını da beraberinde getirir (1, 2). Intraserebral kanamalar, bu komplikasyonlardan biridir $(1,2)$. Bu vakada warfarin kullanımına sekonder gelişen akut bilateral oksipital hematom ve buna bağlı kortikal körlük tablosu tartışılacaktır.

\section{Olgu Sunumu}

Seksen sekiz yaşında erkek hasta, sabah saatlerinde başlayan ani bilateral görme kaybı şikayeti ile acil servisimize başvurdu. Hastanın bilinen kronik obstruktif akciğer hastalığı, hipertansiyonu olduğu; 23 yıl önce miyokard infarktüsü, 3 yıl önce inme geçirdiği ve sonrasında oral warfarin sodyum (5 mg/gün) aldığı öğrenildi. Hastanın kan basıncı 130/70 mmHg, nabzı 70/dakika, ateşi $37^{\circ} \mathrm{C}$ ölçüldü. Fizik muayenede şuur açık, Glaskow Koma Skalası (GKS) E4M6V5 olup, direkt ve indirekt ışık refleksi bilateral pozitifti. Hasta çok az ışığı görebildiğini ifade ediyordu. Laboratuar incelemelerinde INR değeri: 6.24 idi. Tam kan sayımında patolojik bir bulgu saptanmadı. Görme kaybının akut gelişimi ve bilateral olması nedeniyle çekilen beyin tomografisinde bilateral oksipital bölgede lokalize sağda 3×2 solda 2×2 santimetrelik çevresinde hipodens halosu olan hiperdens görünüm izlendi 


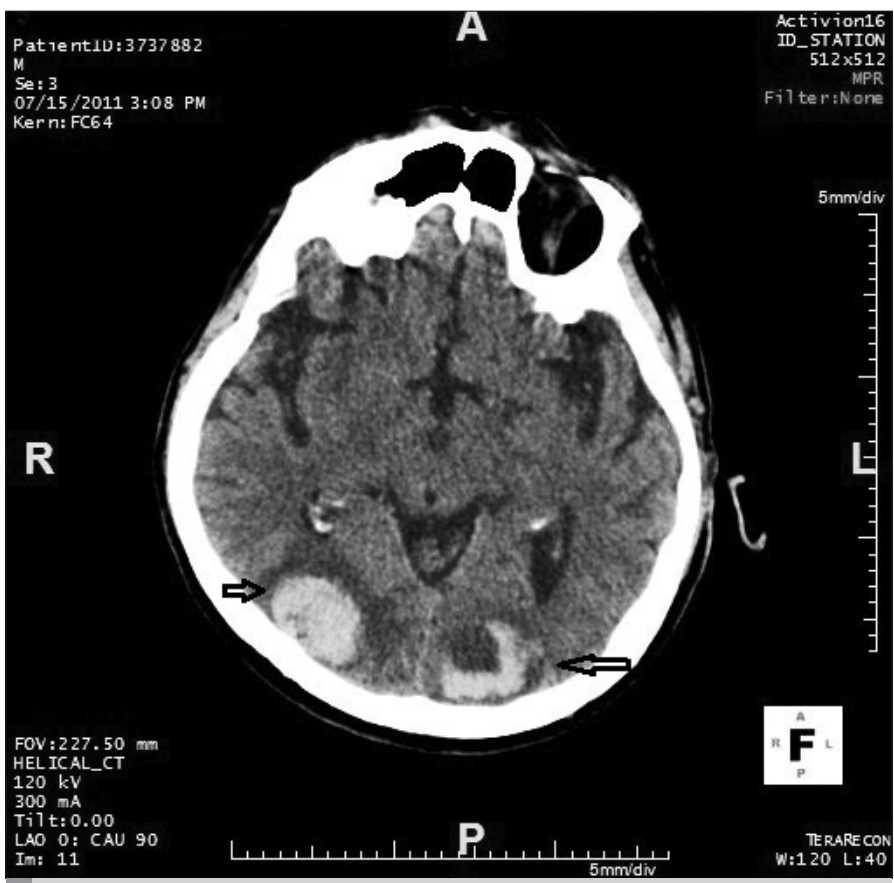

Resim 1. Bilateral oksipital bölgede lokalize sağda $3 \times 2$ solda $2 \times 2$ santimetrelik çevresinde hipodens halosu olan hiperdens görünüm

(Resim 1). Hasta warfarine sekonder bilateral oksipital serebral hemoraji olarak değerlendirildi. Hastada warfarine bağlı INR artışının nedeninin hasta uyumsuzluğundan yada ilaç doz ayarlanmasından kaynaklandığı anlaşılamadı. Hastanın antikoagülan tedavisi kesildi. Parenteral 10 mg K Vitamini ve 3 ünite taze donmuş plazma 150 mililitre/saat hızında infüzyona başlanarak nöroloji kliniğine yatışı yapıldı. 2. gün hastanın INR değeri 1.33 olarak ölçüldü. 2. gün dezoryante olan ve ajite davranışlar sergileyen GKSsi E3M6V3 olarak değerlendirilen hasta beyin ödemi ve kanamada artış olasılığı nedeniyle nöroloji kliniğinin yoğun bakımına nakledildi. Norodol 2.5 mg+2.5 mg IM yapıldı ve 10x3 damla ile oral devam edildi. Yatışının 10. gününde oryante olmaya başlayan ve kontrol tomografisinde (Resim 2) kanama alanında regresyon gözlenen hasta 20. günde kliniğimizden taburcu edildi.

\section{Tartışma}

Kortikal körlük (KK), kortikal vizüel merkezlerin ve genikulokalkarin vizüel yolların lezyonları sonucu meydana gelen körlüktür (1). KKün pek çok nedeni vardır. Bunlar arasında oksipital enfarktüs ve kanamalar, tümör, enfeksiyonlar, oksipital lob epilepsisi, travma, hava embolisi, kardiyak arrest, metabolik hastalıklar ve ilaçlar sayılabilir (1).

Vakamızda KK olup, nedeni oksipital lokalize bilateral hemoraji olarak değerlendirilmiştir. Çok nadir gözlenebilecek olan bu tablo altta yatan presipitan faktörle ilişkilidir (1, 2). Bu tablo; hastada warfarin ilişkili koagülopatiye bağlanmıştır. Antikoagülan ilaçların kullanımının artması ve bu ilaçlara bağlı yan etkileri, acil servislerde sık olarak görülür hale getirmiştir (2). Yan etkilerin sık gözlenmesinde antikoagülan dozunun yanlış ayarlanması, hasta uyumsuzluğu, koagülasyon parametrelerinin belli aralıklarla çalışılmasının ihmali gibi nedenler

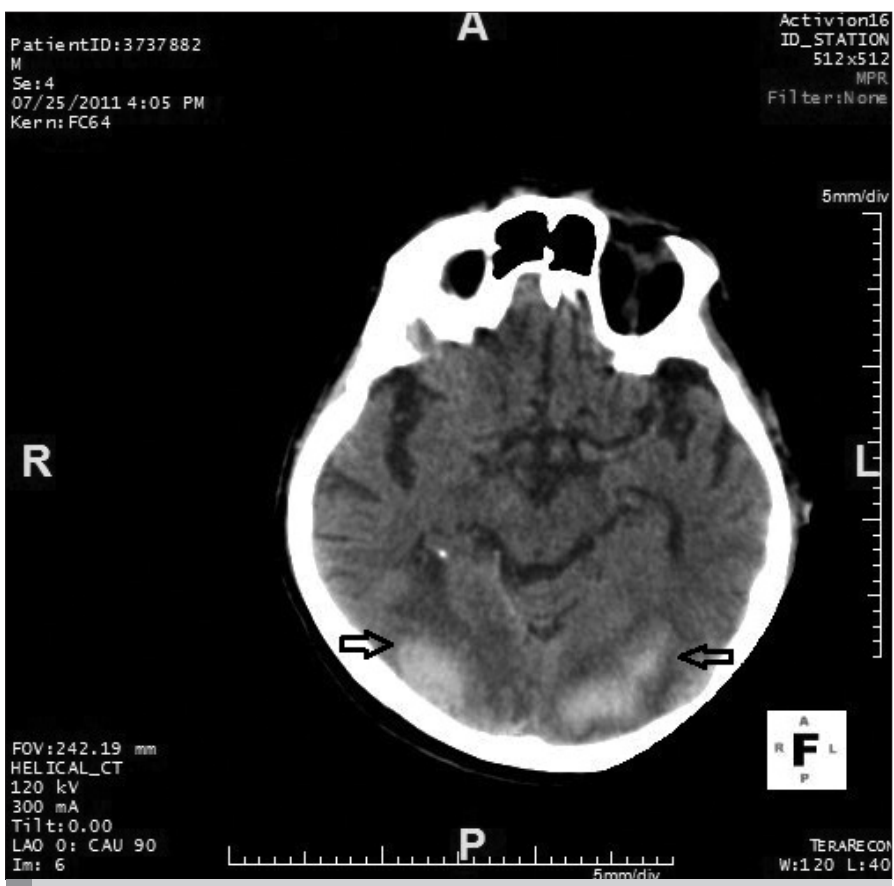

Resim 2. Yatışın 10. gününde regresyon gösteren bilateral oksipital bölgede lokalize çevresinde hipodens halosu olan hiperdens görünüm

daha ön plandadır. Warfarinin en önemli toksik etkisi kanamadır. Antikoagülan kullanan hastalarda INR düzeyinin 6 ve 6 'dan daha fazla olması durumunda hemoraji riskinin arttığı bilinmektedir $(2,3)$. Yapılan bir çalışmada warfarin kullanan hastalarda majör hemoraji oranı \%1-12 olarak bildirilmiştir (4).

Beyin dokusunun kısa süreli de olsa kanamaya bağlı lokal doku basıncındaki artışa ne kadar duyarlı olduğu açıktır (5). Warfarin koagülopatisinde taze donmuş plazma ve K vitamini standart tedavi yöntemidir. Bu tedavinin dezavantajı ise INRdeki düzelme hızının yavaş olmasıdır (5). Bizim vakamızdada 2. günde INR değeri normal düzeye indirilebilmiştir. Bu süre içinde hasta kanama artışı riskine maruz kalmıştır. Kawatama ve arkadaşları warfarin ilişkili subdural hematomlu ve kontüzyonlu hasta grubunda yalnızca vitamin K kullanarak yeterli bir düzelme sağlayamamışlardır (5). Taze donmuş plazma ve K vitamini tedavisi ile INR düzelmesi yaklaşık olarak 0.18 INR/saat olmaktadır (6). Antikoagülasyonun daha hızlı geri döndürülmesi için yüksek volümlerde taze donmuş plazma infüzyonları gerekmektedir (6). Bu da genelde yaşlı ve kronik hastalığı olan antikoagülan kullanıCISı hasta grubunda pulmoner ödem gibi komplikasyonlara neden olabilmektedir (6). Daha da ötesi serebral basınç artışına katkıda bulunabilmektedir (6). Warfarin gibi antikoagülanların kullanımı bu tür kanamaların tedavisinde zorluğu da beraberinde getirmektedir (7). Bu hastaların tedavisinde rekombinant faktör 7A gibi yeni modaliteler de kullanılmaya başlansa da intrakraniyal kanamalardaki gerekli tedavi hızının çok gerisinde oldukları aşikardır (7).

\section{Sonuç}

Antikoagülanların kullanımlarının daha da artacağı açık olup tedavi gelişiminde ilerleme olmaması bu tür mortalitesi ve morbiditesi yük- 
sek intrakranial kanamaların acil servislerde daha sık görülebileceğini düşündürmektedir. Acil hekimi bu komplikasyonları tanıyabilmeli, acil tedavilerini yapabilmeli ve tedavideki zorlukları bilmelidir.

\section{Çıkar Çatışması}

Yazarlar herhangi bir çıkar çatışması bildirmemişlerdir.

\section{Kaynaklar}

1. Prigatano GP, Matthes J, Hill SW, WolfTR, Heiserman JR. Anosognosia for hemiplegia with preserved awareness of complete cortical blindness following intracranial hemorrhage. Cortex 2011; 47: 1219-27. [Crossref]

2. Visser LE, Bleumink GS, Trienekens PH, Vulto AG, Hofman A, Stricker BH. The risk of overanticoagulation in patients with heart failure on coumarin anticoagulants. Br J Haematol 2004; 127: 85-9. [Crossref]
3. Hylek EM, Chang YC, Skates SJ, Hughes RA, Singer DE. Prospective study of the outcomes of ambulatory patients with excessive warfarin anticoagulation. Arch Intern Med 2000; 160: 1612-7. [Crossref]

4. Koo S, Kucher N, Nguyen PL, Fanikos J, Marks PW, Goldhaber SZ. The effect of excessive anticoagulation on mortality and morbidity in hospitalized patients with anticoagulant-related major hemorrhage. Arch Intern Med 2004; 164: 1557-60. [Crossref]

5. Kawamata T, Takeshita M, Kubo O, Izawa M, Kagawa M, Takakura K. Management of intracranial hemorrhage associated with anticoagulant therapy. Surg Neurol 1995; 44: 438-43. [Crossref]

6. Boulis N, Bobek M, Schmaier A, Hoff J. Use of factor IX complex in warfarin related intracranial hemorrhage. Neurosurgery 1999; 45: 1113-9. [Crossref]

7. Bartal C, Freedman J, Bowman K, Cusimano M. Coagulopathic Patients With Traumatic Intracranial Bleeding: Defining the Role of Recombinant Factor VIla. J Trauma 2007; 63: 725-32. [Crossref] 